\title{
Test Method for Plane Stress Fracture Toughness of Thin Sheet Metal
}

\author{
Wen Zheng, Kai-Ye Xiao, Hai Xu, and Zhi-Wei Guo
}

\begin{abstract}
In this paper, the plane stress fracture toughness (KC) of sheet metal similar to 60Si2Mn with a thickness of about $0.9 \mathrm{~mm}$ is measured through the central crack tensile specimen (MT specimen) and the compact tensile specimen (CT specimen). The compliance calibration curve and KR curve are obtained on the basis of the reasonably designed fixture and anti-buckling device. Then the $\mathrm{KC}$ values are calculated by CT specimens. This paper also discussed the minimum plate width when MT specimens satisfied the requirements for validity judgement.
\end{abstract}

Index Terms-Plane stress fracture toughness, MT specimen, CT specimen, compliance calibration curve, $K_{R}$ curve.

\section{INTRODUCTION}

Modern engineering failure problems are often related to some thin-wall metal parts bearing greater working stress, such as thin-wall parts used in pressure vessels or high-speed rotating parts, which are the key structural or functional parts in the whole system. The failure conditions of these thin-wall parts are various, but the process of the cracks extending to unstable fracture is the most difficult to detect and extremely damaging. Therefore, accurate measurement of the plane stress fracture toughness $\mathrm{KC}$ of materials under the working thickness is the primary requirement of the design of thin-wall parts.

Data shows that few tests of the plane stress fracture toughness are conducted on thin plates with a thickness of less than $1 \mathrm{~mm}$. On one hand, structures cannot reach such a small thickness under high stress; on the other hand, the extreme thickness will cause serious buckling of the specimen, so that it is difficult to satisfy the ideal test conditions. Therefore, it is particularly important to design properly the fixture and anti-buckling device. In this paper, $60 \mathrm{Si} 2 \mathrm{Mn}$-like rolled steel sheet with about $0.9 \mathrm{~mm}$ thickness is selected for KR curve test of central crack tensile (MT) and compact tensile (CT) specimens to obtain the $\mathrm{KC}$ values of the material [1].

\section{DESIGN OF THE SPECIMENS AND FIXTURES}

The key lies in the design of thickness $\mathrm{B}$ and width $\mathrm{W}$ of plane stress fracture toughness specimens. In this paper, the thickness B of two specimens is close to $0.9 \mathrm{~mm}$ under

Manuscript received May 12, 2019; revised July 11, 2019.

The authors are with Research Institute of Physical and Chemical Engineering of Nuclear Industry, Tianjin 300180, China (Corresponding author: Wen Zheng; e-mail: zw19840801@163.com). actual working condition, and $\mathrm{W}$ is different. To ensure that the test will not be affected by anisotropy, the length of the specimen is uniformly in the rolling direction (i.e. L-T direction), and the other mechanical parameters related to $\mathrm{K}_{\mathrm{R}}$ calculation are measured by the same specimen preparation method.

\section{A. MT Specimens}

Theoretically, the greater width of MT specimen is beneficial to the test, but practically the width is often limited by material specifications and the stroke of test machine. In this paper, the width of MT specimen W is $100 \mathrm{~mm}$ and the length of loaded surface is greater than $3 \mathrm{~W}$. As shown in Fig. 1, multi-pin clamp is used to ensure uniform load distribution. The $\mathrm{L}$ segment is a prefabricated crack by wire cutting (wire diameter is about $0.12 \mathrm{~mm}$ ). The length is different, depending on the test requirements. Fig. 2 represents the fixture [2].

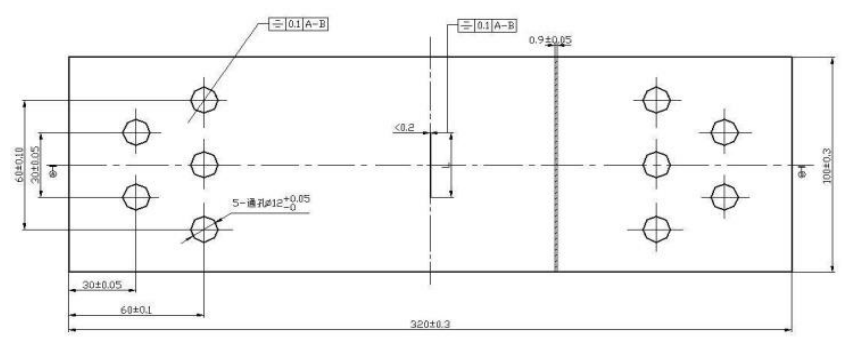

Fig. 1. MT specimens.

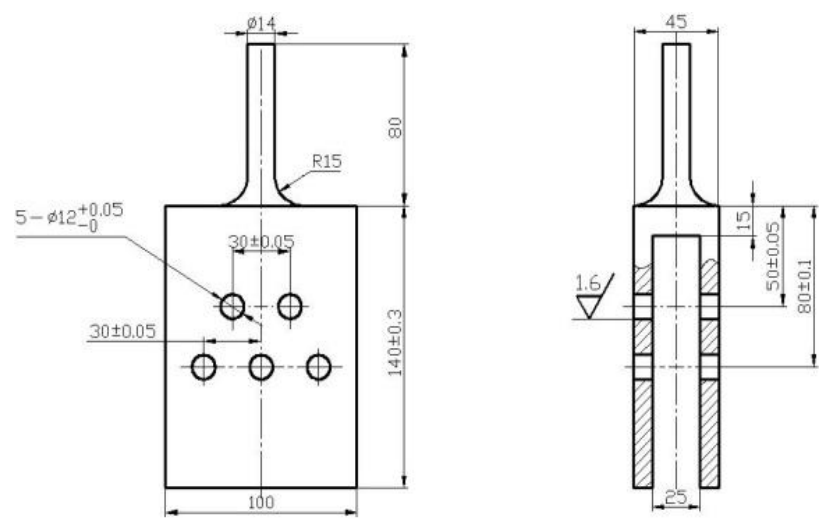

Fig. 2. Fixture of MT specimens.

For a cracked plate under unidirectional tension, the crack face bears compressive stress of the same magnitude as the longitudinal tensile stress. If the thickness of the plate is small, the compressive stress is likely to buckle the section of the plate adjacent to the crack, especially in anisotropic materials, the crack itself is easy to bend in the grain orientation with a weak resistance to crack propagation, and the buckling of the specimen will aggravate the occurrence of this situation, so it is necessary to give sufficient 
constraint to the specimen in the buckling direction. As shown in Fig. 3, the specimen is clamped with two anti-buckling plates and locked with bolts around, leaving a window large enough in the plate to deform the extensometer and observe the crack growth [3]. In practice, solid lubricant should be applied between anti-buckling plate and specimens to reduce friction, and lubricant should be prevented from entering the crack tip.
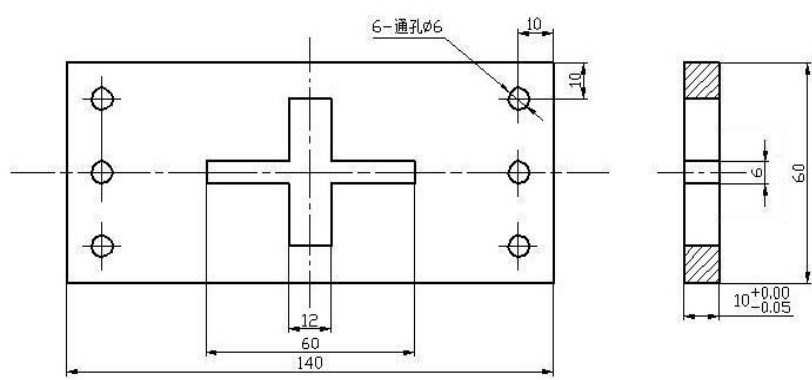

Fig. 3. Anti-buckling plate of MT specimens.

\section{B. CT Specimens}

The width $\mathrm{W}$ of the CT specimen is the horizontal distance from the loading line to the edge of the crack tip of the specimen. In this paper, $W=80 \mathrm{~mm}$. As shown in Fig. 4, the dovetail groove on the right side of the specimen is designed to fit the COD extensometer. Fig. 5 represents the fixture [4].
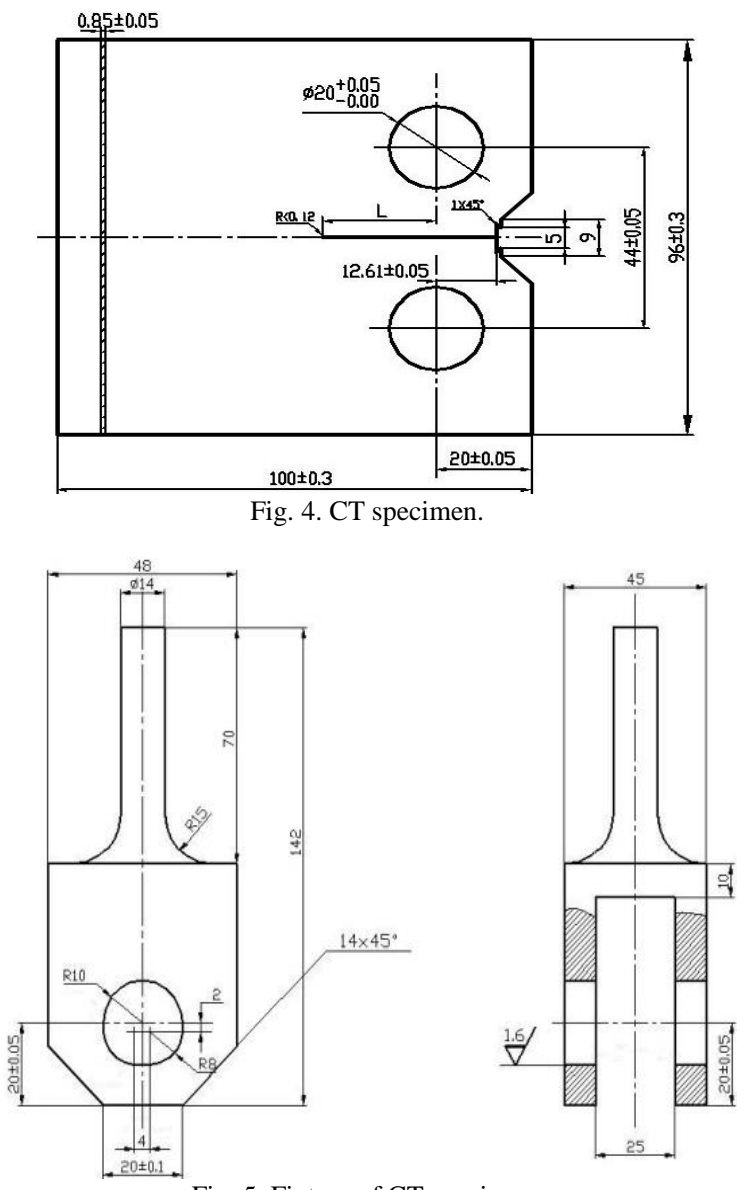

Fig. 5. Fixture of CT specimen.

The deformation of CT specimens during the loading process is different from that of MT specimens, for that the single dowel is adopted. It is difficult to maintain the tensile force in a plane because of the gap between the dowel hole and the dowel shaft, and the specimen is easy to be warped. At the same time, the tensile deformation of the specimens is large, and it is necessary to maintain good anti-buckling ability and observation effect in a long distance. Therefore, the lower dowel is made to maintain free stroke in the stretching direction, as shown in Fig. 6.

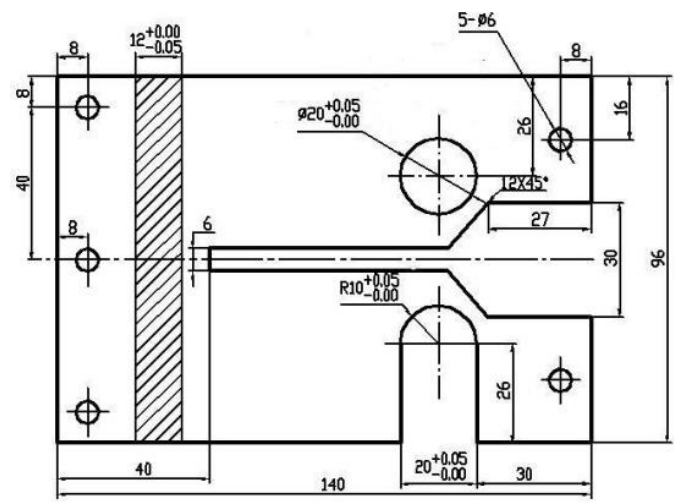

Fig. 6. Anti-buckling plate of CT specimens.

\section{Verification of anti-Buckling Effect}

Refer to the relevant regulations of ASTM E561 [1], a periodic partial unload of the specimen is performed by reversing the deformation direction to detect whether buckling or friction are affecting, as shown in Fig. 7. If the slopes differ by more than $2 \%$, or if one or both have no linear range, or if the unload-reload trace forms a loop, then buckling or friction may be affecting the test results sufficiently. It is necessary to adjust the tightness of the anti-buckling plates, or add more lubricant.

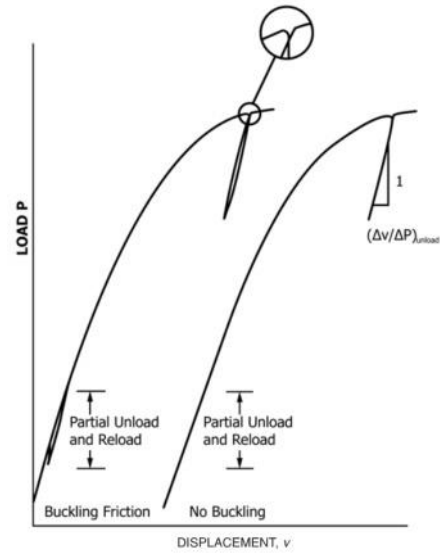

Fig. 7. Detection of bucking from compliance test records.

\section{EXPERIMENT}

\section{A. Compliance Calibration Curve}

As the effective crack length must be corrected by compliance calibration curve, and there is an error between the result calculated by the empirical formula and the measured result, this paper presents a compliance calibration curve obtained by experiment. Specimens were prepared at the values of $0.1,0.2,0.3,0.4,0.5,0.6$ and 0.7 for $2 a_{0} / \mathrm{W}$ (i.e. $\mathrm{L} / \mathrm{W}$ of MT specimen) and $a_{0} / \mathrm{W}$ (i.e. L/W of CT specimen), then the tensile tests at single direction were carried out at the rates of $0.5 \mathrm{kN} / \mathrm{s}$ and $0.03 \mathrm{kN} / \mathrm{s}$ respectively, and the P-2V curves were recorded, as shown in Fig. 8 and Fig. 9 
[5], [6].

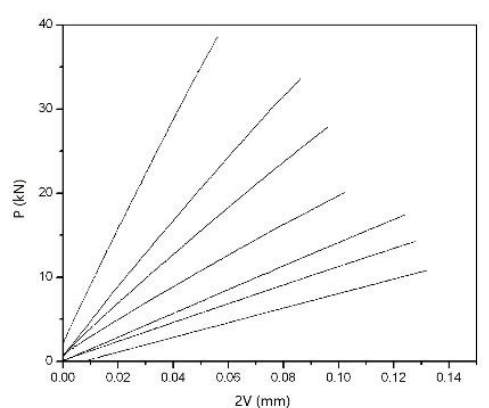

Fig. 8. P-2V curves of MT specimens.

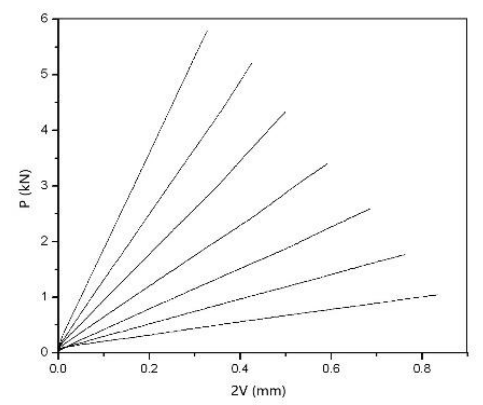

Fig. 9. P-2V curves of CT specimens.

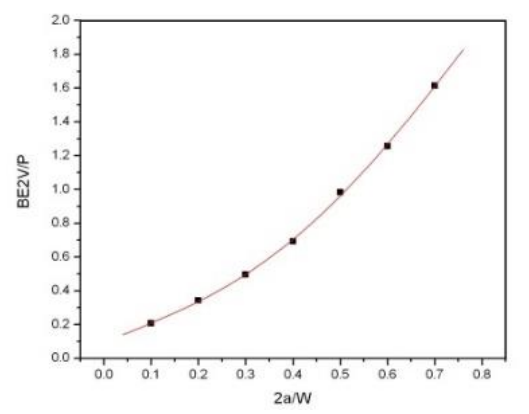

Fig. 10. Compliance calibration curve of MT specimens.

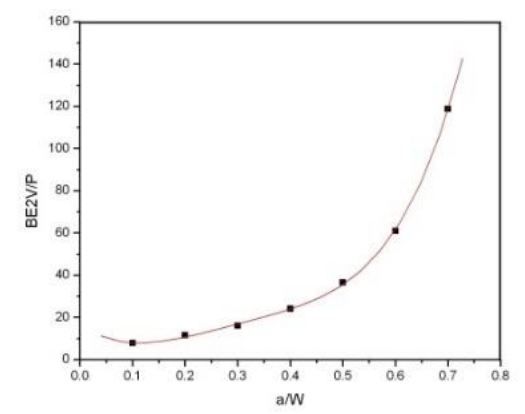

Fig. 11. Compliance calibration curve of CT specimens.

Based on the slope of $\mathrm{P}-2 \mathrm{~V}$ curve, BE2V/P-2a/W and BE2V/P-a/W curves were made, as shown in Fig.10 and 11, then the formula of compliance calibration curve can be fitted:

For the MT specimen, if the value of $2 \mathrm{a} / \mathrm{W}$ belongs to $(0.1,0.7)$, $0.7)$,
If there is no condition to test the compliance calibration curve, the empirical formula in ASTM E561 can be used [1]. In this paper, the effective crack length calculated by empirical formula may be relatively smaller, so it is still necessary to measure the compliance calibration curve.

\section{B. Test of Formal Specimens}

Formal specimens need prefabricated cracks through fatigue. Two specimens with $L=30 \mathrm{~mm}$ are taken, and the length of the crack in MT specimen is $35 \mathrm{~mm}$, which was fatigued with $F_{\max }=22 \mathrm{kN}, F_{\min }=2.2 \mathrm{kN}, f=10 \mathrm{~Hz}$; the length of the crack in CT specimen is $33 \mathrm{~mm}$ with $F_{\max }=1.5 \mathrm{kN}$, $F_{\text {min }}=0.15 \mathrm{kN}, f=10 \mathrm{~Hz}$, and then $\mathrm{P}-2 \mathrm{~V}$ curves are tested. As shown in Fig. 12 and 13, the fatigue crack grows steadily, and the tensile fracture presents 45 degree angle, which proves that the anti-buckling device is effective [7], [8].

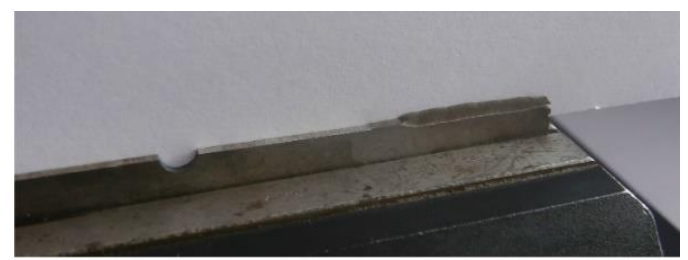

Fig. 12. Fracture of MT specimen

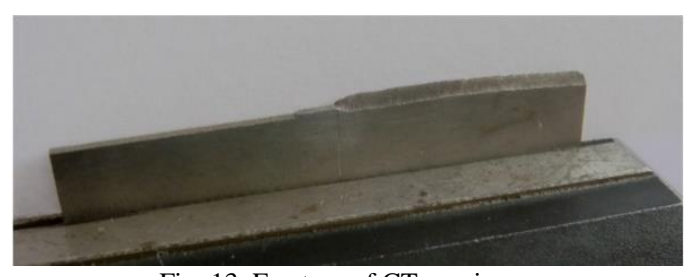

Fig. 13. Fracture of CT specimen.

As shown in Fig. 14 and Fig. 15, the P-2V curves of MT formal specimens show some difference in maximum loads by contrast with CT test. It is caused by the systematic error of the MT test or the insufficient width of MT specimens, which still needs more tests to verify.

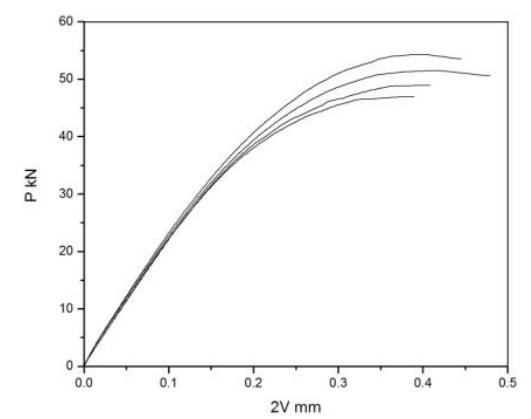

Fig. 14. P-2V curves of MT formal specimens

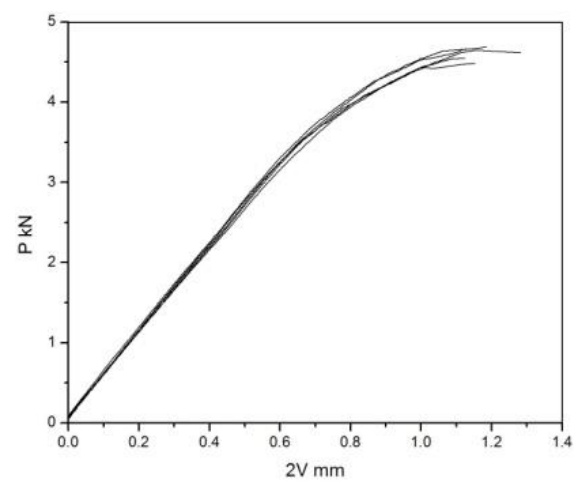

Fig. 15. P-2V curves of CT formal specimens. 


\section{DATA PROCESSING AND DisCUSSION OF FINDINGS}

\section{A. Plot of the $K_{R}$ Curve}

Starting from the end point $A$ of the elastic section of $\mathrm{P}-2 \mathrm{~V}$ curve as the starting point, as shown in Fig. 16, draw at least five secant lines uniformly in the non-proportional part of the curve, and calculate the compliance value BE2V/P of each intersection point. The effective crack length corresponding to each intersection point is calculated from the compliance calibration curve. The crack length corresponding to point $\mathrm{A}$ is the initial crack length $a_{0}$. If the error between the value and measured $a_{0}$ exceeds $0.003 \mathrm{~W}$, it should be corrected. Taking the compliance value of point $\mathrm{A}$ and the measured $a_{0}$ of point $\mathrm{A}$ as a point, move the compliance calibration curve vertically to pass through this point, and then check the effective crack length a of other points can be found on the curve after moved.

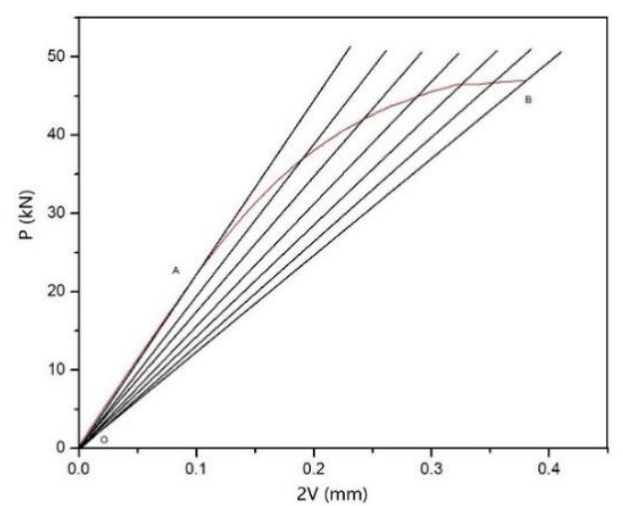

Fig. 16. Analysis of P-2V curve.

Based on the load and effective crack length of each point, the corresponding $K_{R}$ value can be calculated. The calculation results are shown in Table I and Table II.

For MT specimens, use the following calculation formula
[1]:

For CT specimens, use the following calculation formula:

And

(effective range $a / W>0.35$ )

\section{B. Validity Judgement}

The validity of $K_{R}$ values should be judged. For MT specimens, the net section stress $\sigma_{N}$ is required to be less than the yield strength $\sigma_{Y}$ (The $\sigma_{Y}$ of 60Si2Mn-like material has been measured as $1109 \mathrm{MPa}$ ), and for CT specimens, the length of the unbroken ligament is required to be more than eight times the length of the plastic zone, as shown by the following expressions:

for MT specimens,

for CT specimens,

As shown in Table I and Table II, the measured $\mathrm{K}_{\mathrm{R}}$ values of MT specimens cannot satisfy the validity criterion, so the data points are invalid, which may be caused by the insufficient width of the plate, but all data points of CT specimens are valid.

TABLE I: CALCULATION RESULTS OF MT SPECIMENS

\begin{tabular}{cccccccc}
\hline \hline & $W(\mathrm{~mm})$ & $B(\mathrm{~mm})$ & $P(\mathrm{kN})$ & $2 a(\mathrm{~mm})$ & $K_{R}\left(\mathrm{MPa} \cdot \mathrm{m}^{1 / 2}\right)$ & $\sigma_{N}(\mathrm{MPa})$ & Criterion $\sigma_{N}<1109$ \\
\hline 1 & 100 & 0.86 & 22.46 & 34.70 & 65.99 & 400 & valid \\
2 & 100 & 0.86 & 27.95 & 35.65 & 83.61 & 505 & valid \\
3 & 100 & 0.86 & 32.96 & 36.98 & 101.10 & 608 & valid \\
4 & 100 & 0.86 & 36.98 & 38.66 & 117.00 & 701 & valid \\
5 & 100 & 0.86 & 41.08 & 41.31 & 136.42 & 814 & valid \\
6 & 100 & 0.86 & 43.09 & 43.07 & 147.69 & 880 & valid \\
7 & 100 & 0.86 & 45.07 & 45.66 & 161.80 & 964 & valid \\
8 & 100 & 0.86 & 45.69 & 46.64 & 166.88 & 996 & valid \\
9 & 100 & 0.86 & 46.21 & 47.62 & 171.75 & 1026 & valid \\
10 & 100 & 0.86 & 46.52 & 48.54 & 175.78 & 1051 & 1109 \\
11 & 100 & 0.86 & 46.75 & 50.98 & 184.48 & 1198 & valid \\
12 & 100 & 0.86 & 46.94 & 54.42 & 197.15 & invalid \\
\hline \hline
\end{tabular}

TABLE II: CALCULATION RESULTS OF CT SPECIMENS

\begin{tabular}{|c|c|c|c|c|c|c|c|c|}
\hline & $W(\mathrm{~mm})$ & $B(\mathrm{~mm})$ & $P(\mathrm{kN})$ & $a(\mathrm{~mm})$ & $\triangle a(\mathrm{~mm})$ & $K_{R}\left(\mathrm{MPa} \cdot \mathrm{m}^{1 / 2}\right)$ & $8 r_{y}(\mathrm{~mm})$ & Criterion $W-a>8 r$ \\
\hline 1 & 80 & 0.87 & 3.02 & 33.16 & 0 & 92.77 & 8.9 & valid \\
\hline 2 & 80 & 0.87 & 3.48 & 33.65 & 0.49 & 108.99 & 12.3 & valid \\
\hline 3 & 80 & 0.87 & 3.68 & 33.97 & 0.81 & 116.50 & 14.1 & valid \\
\hline 4 & 80 & 0.87 & 3.85 & 34.29 & 1.13 & 123.03 & 15.7 & valid \\
\hline 5 & 80 & 0.87 & 4.06 & 34.95 & 1.79 & 132.75 & 18.2 & valid \\
\hline 6 & 80 & 0.87 & 4.25 & 35.64 & 2.48 & 142.39 & 21.0 & valid \\
\hline 7 & 80 & 0.87 & 4.33 & 36.01 & 2.85 & 146.92 & 22.3 & valid \\
\hline 8 & 80 & 0.87 & 4.43 & 36.51 & 3.35 & 152.85 & 24.2 & valid \\
\hline 9 & 80 & 0.87 & 4.53 & 37.03 & 3.87 & 159.35 & 26.3 & valid \\
\hline 10 & 80 & 0.87 & 4.65 & 38.03 & 4.87 & 169.51 & 29.7 & valid \\
\hline 11 & 80 & 0.87 & 4.62 & 39.79 & 6.63 & 179.95 & 33.5 & valid \\
\hline
\end{tabular}




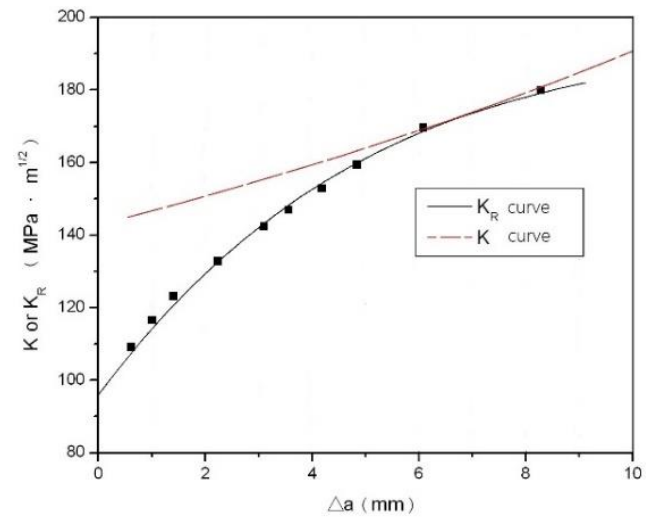

Fig. 17. $K_{R}$ curve of CT specimens.

Based on Table II, the $K_{R}$ curve of the CT specimen is made (Fig. 17). And the formula is fitted:

$$
K_{R}=e^{4.582} \times(\Delta a+0.8421)^{0.2789}
$$

\section{Determination of $K_{C}$ Value}

The $\mathrm{K}$ curve is drawn on the $K_{R}$ curve. $K$ is the stress intensity factor, which changes with load and crack length. By adjusting the $P$ value constantly, the $K$ curve will be tangent to the $K_{R}$ curve. The $K_{R}$ value corresponding to the tangent point is the $\mathrm{K}_{\mathrm{C}}$ value of the material. The calculated result is $K_{C} \approx 170 \pm 4 \mathrm{MPa} \cdot \mathrm{m}^{1 / 2}$.

\section{Discussion of Width}

Based on $\mathrm{Kc} \approx 170 \pm 4 \mathrm{MPa} \cdot \mathrm{m}^{1 / 2}$, the plastic zone size $r_{y}$ is calculated to be $3.74 \mathrm{~mm}$. For MT specimens, the width of $100 \mathrm{~mm}$ used in this paper is approximate to $27 r_{y}$ [1], which does not meet the test requirements. If the width $\mathrm{W}$ is further increased to be $W>35 r_{y}$ [2], [9], $\mathrm{W}_{\min }$ should be at least $131 \mathrm{~mm}$.

The width of CT specimen is $80 \mathrm{~mm}$, which is greater than $16 r_{y}=59.2 \mathrm{~mm}$, and there is some margin. The specimens of this specification can be used in a small range of $K_{C}$ values. Data show that the test results of the two types of specimen are consistent [10], and CT specimen has lower requirement for plate width, so it is easier to get effective results for this material.

\section{CONCLUSION}

Based on the $K_{R}$ curve method, MT and CT test schemes are designed for $60 \mathrm{Si} 2 \mathrm{Mn}$-like rolled steel sheet with thickness of about $0.9 \mathrm{~mm}$. The reasonable design of anti-buckling device can make the test more accurate. For this paper, effective results can be measured more easily by CT test scheme.

\section{REFERENCES}

[1] ASTM E561-15a. Standard Test Method for $K_{R}$ Curve Determination.

[2] HB 5261-1983. Test method for $K_{R}$ curves of metal plates.
[3] W. Xie, "Determination of fracture toughness and K-R curve for 2524-T3 aluminum alloy," Advanced Materials Research, vol. 1, pp. 1039-1042, 2011.

[4] ASTM D5045-14. Standard Test Methods for Plane-Strain Fracture Toughness and Strain Energy Release Rate of Plastic Materials.

[5] W. Y. Chu, Fundamentals of Fracture Mechanics, Beijing: Science Press, 1979, pp. 110-133

[6] D. E. Mccabe, "Compliance calibration of specimens used in the R-curve practice," ASTM Special Technical Publication, vol. 632, pp 82-96, 1977.

[7] D. Brock, Elementary Engineering Fracture Mechanics, Beijing: Science Press, 1980, pp. 194-195

[8] Y. Z. Lu, Engineering Fracture Mechanics, Xi 'an: Xi'an Jiaotong University Press, 1986, pp. 82-84

[9] Teaching and Research Office of Material Mechanics, "Study on the determination of plane stress fracture toughness $\mathrm{Kc}$ of 30CrMnSiNi2A steel and related problems," Journal of Northwestern Polytechnical Universit., 1998.

[10] B.-R. Hu, "Effect of specimen type on $K_{R}$ curve," Metallurgical Analysis, vol. 26, pp. 177-179, 2006.

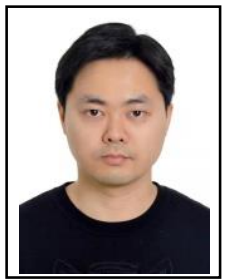

Wen Zheng was born in Hubei, China on August 1, 1984. He graduated from the School of Materials Science and Engineering, Sichuan University, majoring in metal materials engineering in 2006.

$\mathrm{He}$ works at the Institute of Physical and Chemical Engineering of Nuclear Industry and serves as the deputy minister of Planning and Senior Engineer. His main research is metal materials, testing technology and anti-corrosion process related fields.

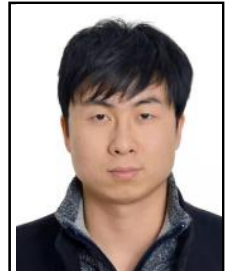

Hai Xu was born in Henan China on July 25, 1988 $\mathrm{He}$ graduated from the School of Mechanical Engineering of Tianjin University in 2011 with a major in mechanical design and manufacturing and automation.

$\mathrm{He}$ works at the Institute of physical and chemical engineering of Nuclear Industry as an engineer. He mainly engaged in magnetic materials, powder metallurgy and automation technology related fields.

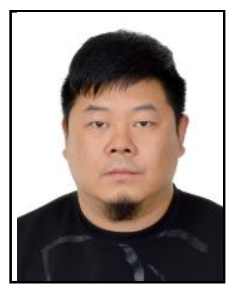

Kaiye Xiao was born in Tianjin,China on May 24, 1975. He graduated from the School of physical and chemistry with a major in inorganic non-metallic materials, Beijing University of Science and Technology in 1998. In 2010, he obtained a master's degree in materials engineering from school of materials of Tianjin University.

$\mathrm{He}$ works at the Institute of physical and chemical engineering of Nuclear Industry, serves as the director of the workshop, and is a senior enginee at the researcher level. His main research is metal materials, magnetic materials and powder metallurgical process related fields.

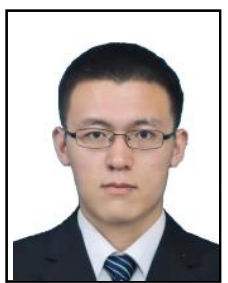

Zhiwei Guo was born in Henan, China on January 8 1989. He graduated from the School of Mechanical Engineering of Zhengzhou University in 2011 with a major in mechanical design and manufacturing. In 2014, he graduated from the School of Mechanical Engineering of Tianjin University with a master degree of mechanical design.

$\mathrm{He}$ works at the Institute of physical and chemical engineering of Nuclear Industry as an engineer. Mainly engaged in machinery design manufacturing, automation technology and magnetic materials related fields. 